Article

\title{
Inclusive Vision Versus Special Education Reality
}

\author{
James M. Kauffman ${ }^{1, *}$ and Garry Hornby ${ }^{2, *}$ \\ 1 Department of Special Education, University of Virginia, Charlottesville, VA 22904, USA \\ 2 Institute of Education, University of Plymouth, Drake Circus, Plymouth PL4 8AA, UK \\ * Correspondence: jmk9t@virginia.edu (J.M.K.); garry.hornby@plymouth.ac.uk (G.H.)
}

Received: 14 August 2020; Accepted: 17 September 2020; Published: 22 September 2020

\begin{abstract}
The reasons are examined for the disparity between the inclusive vision espoused by Article 24 of the United Nations Convention on the Rights of Persons with Disabilities and the reality of the limited extent of inclusion in education systems worldwide. First, the leadership of key senior academics in the field of special education is considered to have been misguided in promoting a vision of full inclusion despite the lack of research evidence for the benefits of inclusive education over traditional special education provision. Second, attitudes toward and the treatment of people with disabilities have a long and complex history, and in this, many proponents of inclusion have been critical of 20th century special education. In particular, they claim that the sorting, labelling and categorizing required by special education have negative implications. Third, educators have been encouraged to imagine a system of education that is limitless, in the sense that all children with disabilities can be included in general education. This is because it is envisaged that general education classrooms will become so flexible that there will be no limits to the accommodation of students with disabilities, regardless of the nature or severity of their special educational needs. Fourth is the issue that deciding a student's placement for education requires a judgment call and that, since human judgment is fallible, errors of judgment will always be made. Fifth, commitments to inclusion require that educators consider the practical, reality-based implications, whereas this has not been the case for many supporters of full inclusion. In conclusion, inclusion in the sense of students being physically present in general education classrooms is not considered as important as inclusion in the reality of being engaged in a program of instruction that is meaningful and challenging. Therefore, we consider that, rather than becoming extinct, special education needs to continue to be developed, disseminated and rigorously implemented in schools. Key special education strategies and approaches must co-exist with those from inclusive education, in order to provide effective education for all young people with special educational needs and disabilities.
\end{abstract}

Keywords: disability; special education; inclusion; inclusive education

\section{Inclusive Vision versus Special Education Reality}

The United Nations Convention on the Rights of Persons with Disabilities (UNCRPD) Article 24, in General Comment Number Four [1], called for all countries to implement fully inclusive education systems as soon as possible. This was partly based on the controversial statement noted in General Comment Number Four that children with disabilities educated in segregated settings receive an education of inferior quality [1]. Given this unsubstantiated claim, important questions about the implications of moving to and operating single inclusive education systems, and also about the future of special education provision, need to be addressed [2]. This is because the policy directive of UNCRPD Article 24 foreshadows the extinction of special education as it exists today [3-5].

However, in contrast, the recently published Global Education Monitoring Report on Inclusive Education [6] presented international survey findings suggesting that predictions of the demise of 
special education may be premature. The report stated that "National policies emphasize segregation in $5 \%$ of countries, partial segregation in $45 \%$, integration in $12 \%$ and inclusion in $38 \%$." Furthermore, the report also stated that "Worldwide, laws emphasize segregation in $25 \%$ of countries, partial segregation in $48 \%$, integration in $10 \%$ and inclusion in $17 \% "$. Therefore, it is clear that, in reality, the global picture is one in which the vast majority of countries maintain partially segregated or fully segregated special education settings to provide for a large proportion of their children with special educational needs and disabilities. This is far from the UNCRPD vision of all countries moving to fully inclusive education systems [1]. It seems that, currently, only a minority of young people with special educational needs and disabilities are educated in fully inclusive schools, despite most countries having ratified UNCRPD Article 24.

So, how have we reached the situation where there is a substantial difference between the inclusive vision espoused by one agency of the United Nations and the actual reality of the extent of inclusion in education systems worldwide reported by another? We suggest in this article that there are a wide variety of reasons for this disparity, and these are explained below.

\section{Misguided Leadership of Key Senior Academics in the Field of Special Education}

During the past 40 years, some senior academics in key positions in the field of special education in the UK, USA, and Australasia appear to have been out of touch with the reality faced by many practitioners and parents of children with special educational needs and disabilities. They have also paid insufficient attention to developments in the field of special education that have occurred over this period and to the research evidence that has emerged on effective education for young people with special educational needs and disabilities. It has been suggested that "Good will toward special education has been undermined by years of unwarranted criticism from within our profession and from others, deliberate deconstruction, and proposals for reform that are unworkable" [7] (p. 70).

Some senior academics in key positions in the field of special education have promoted a vision of full inclusion, now often portrayed by the term, "All Means All", in which all children, with no exception, must be educated in mainstream school classrooms alongside their age peers. This policy advice has been promoted despite the widely reported concerns of teachers and parents, and the lack of research evidence for the advantages of inclusive education for some children over traditional special education provision and placements [2,8]. Why have these senior academic leaders continued to promote a vision of full inclusion and to ignore evidence of its inappropriateness? Several reasons are possible, and we discuss them in turn.

First, it has been easier, and therefore very appealing, to promote a clear and simple idea to explain the complex issue of how to provide optimum education for children with a wide range of special educational needs and disabilities. Full inclusion is a clear and simple policy, in which all children, with no exception, are educated in mainstream school classrooms alongside their age peers. So, this policy is easy to promote and disseminate. However, there is a major problem, as highlighted by the well-known aphorism attributed to H. L. Menken: "For every complex problem there is a solution that is simple, neat, and wrong."

The overly simplistic vision of full inclusion promoted by key senior academics in the field of special education was mainly based on a human rights justification, exposed as naïve and false after consideration of issues of human rights and moral rights [3,9]. Full inclusion has also been shown to be flawed and unrealistic when the elements of its theory, policy, research and practice are carefully examined, as outlined in an article that asks the question, "inclusion or delusion, can one size fit all?" [10]. These glaring flaws in the vision of full inclusion have been highlighted in the published literature for over 40 years now, but these same senior academics in key positions in the field of special education have consistently failed to engage with them, either in the academic literature or in open debate, preferring to continue to promote their simplistic vision of full inclusion.

Second, once full inclusion had been set up by senior academic leaders as the gold standard for the education of all children with special educational needs and disabilities, it became much easier 
for other scholars, researchers, and practitioners in the field to support it rather than to criticize it. This was particularly the case because full inclusion was presented as being underpinned by the issue of human rights, so that criticizing the policy of full inclusion was seen as somehow suggesting that children with disabilities would be denied their human rights. Therefore, a situation developed as illustrated by the tale of the "emperor's new clothes", whereby people did not want to stand out by pointing out that the emperor was naked, so went along with the majority of people by pretending that the emperor's new clothes were wonderful [11]. In the same way, few special educators have been prepared to be critical of the policy of full inclusion, as it has been far easier to go along with this theory than to risk becoming a pariah by being skeptical of it. Hence, there has been a torrent of articles and books singing the praises of inclusive education, but only a limited literature that is skeptical or critical of it.

Third, the promotion of full inclusion by key senior academics has influenced the careers of less experienced academics in the field of special education. This is because of the policies of academic promotion committees, funding bodies and journal editors. It became clear that obtaining academic promotions favored those supporting inclusion or inclusive education. Of course, only anecdotal evidence is available to support this assertion. For example, one of the authors, as a young academic, after giving a keynote presentation in the north of England in the late 1980s that was critical of inclusion, was asked "Don't you want to get promoted?"

We observe also that research and development grant proposals related to the furtherance of inclusive education seem far more likely to obtain funding than do proposals to conduct research regarding special schools, classes, or education that is obviously different for students with special educational needs or disabilities from that offered to all other students.

It also became clear that journals in the field of special education favored publications reporting examples of inclusive education, and articles critiquing this or being critical of inclusion have been difficult to publish. Bias is apparent in the decisions of some journal editors regarding papers on topics related to special and inclusive education. Perhaps this is understandable, given differences of opinion regarding how facts are established, what constitutes reliable evidence, and the meaning and interpretation of data [12]. However, in what has been described as a "new normal" [13], some editors seem loathe to publish papers that do not tout the wisdom, logic, legal basis, or evidence for inclusion of all students with disabilities in general education. An indication of this is that the International Journal of Inclusive Education now has 14 issues per year in an attempt to accommodate the torrent of articles supporting inclusion, whereas most special education journals publish far fewer issues per year, and some have revised their titles to include the words "inclusion" or "inclusive" in attempts to attract more submissions.

Fourth, the policy of full inclusion espoused by senior academics has played into the hands of education authorities wanting to save money by closing special education schools and classes, to the detriment of educational outcomes for young people with special educational needs and disabilities. One example of this was the decision by a local education authority, driven by a policy of inclusion, to close a special school for young people with moderate learning difficulties in the north of England in the late 1980s, with the ex-students being transferred to mainstream schools. A follow-up study [14] found that ex-students who were transferred into special classes within mainstream schools, and their parents, were more satisfied with their placements than those who had been transferred into mainstream classrooms. A further follow-up study conducted a few years after the ex-students had left school [15] found that outcomes for those young people that had been transferred to mainstream schools, in either special classes or mainstream classrooms, was very poor, with the vast majority of young people without jobs and not living independently. A major reason for this was considered to be that these young people had missed out on the vocationally orientated curricula and work experience placements that they would have undertaken in the special school that had been closed. So it appears that the decision of the education authority to follow the policy of inclusion, and save money in closing the special school, had resulted in the young people involved being denied an education that would enable them to be included in their communities once they left school. 
Another example was the closure of a residential special school for children with emotional and behavioral difficulties in New Zealand. This school had operated effectively for many years and was considered by many people to provide a model program for the education of such children. However, following the policy of full inclusion, promoted by some senior New Zealand academics in the field of special education, the Ministry of Education adopted a policy of closing special schools and had already closed some which had been experiencing difficulties. Closure was more difficult to justify in this case, since the school had long operated effectively. So the Ministry commissioned a senior academic known to support full inclusion to do a review of the literature on provision for children with emotional and behavioral difficulties focusing on a wraparound approach as an alternative to special school placement. Despite senior colleagues warning this academic that the report would be used to justify closing the special school, the review was completed and subsequently the school was indeed closed.

Finally, another example is the determination by a full inclusion advocacy group to close a special school preferred by a student with disabilities and her mother. The girl was brought home from the special school and enrolled in a general education environment by her mother. But her inclusion failed to meet her needs and make her happy. As reported [16] (p. 16):

Besides feeling lonely and out-of-it and being away from her friends, she wasn't learning much, if anything. So, she began begging her mom to go back to the special school out of state. There, she said, she had friends and could do lots of fun things, like be a cheerleader, ride horses, and learn to swim.

In conclusion, it is clear that views of senior academics in key positions in the field of special education have been influential in the recent history of policies and attitudes towards education for young people with special educational needs and disabilities. In many ways, we seem not to have learned from our history $[13,17,18]$.

\section{History: Its Vicissitudes and Lessons}

Attitudes toward and treatment of people with disabilities have a very long and complex history, and some people now find many of the attitudes and practices of the 20th century distasteful. For example, two proponents of inclusion who are critics of 20th century special education wrote:

Special education plays a sorting role, both for those consigned to it and for those students who remain in general education. It limits expectations of the former, and gnarls the attitudes of the latter... Thus, the system of special education, and the attitudes towards disability that undergird it, have harmful consequences for both those labeled "disabled" and those not. [19] (pp. 767-768)

Some might observe that although sorting, labeling, and categorizing may be seen to have negative implications and can be done clumsily and inappropriately, they are practices that cannot be avoided without losing the ability to communicate clearly and effectively about disabilities. The real challenge is finding ways to sort, label, and categorize better, not to eliminate these essential tasks. They simply cannot be eliminated if disabilities are to be recognized and individuals with them are to receive special services. Even the field of Disability Studies must sort and label (and, therefore, categorize) or it cannot exist. That is, persons must be sorted (said to have or not to have disabilities) or the category of disabilities is meaningless and, therefore, cannot be studied. Without labels and categories, which imply sorting in some rational way, Disability Studies becomes the study of everyone, a hollow and unfocused study of homo sapiens. That is, if everyone has a disability, then there is no need to study the stigma that can accompany a disability, only the stigma that goes with being a human being [11].

However, given the fact that sorting, labeling, and categorizing are necessary for any kind of thinking about or analysis of phenomena, including those phenomena that go with being homo sapiens, 
one might wonder about the attitudes towards disability that undergird special education and the consequences of being labeled as having a disability related to education. It is important to know what these attitudes are, how and to what extent they are harmful, and whether they can be avoided, if they are actually harmful, or the alternative benefits they may have. It is clear that histories of special education do not suggest that it is a malicious social project, or that the attitudes toward disability that undergird it are more harmful than helpful [20,21].

We now know that some people view special education and its ideas and ideals dating from 1975 as malicious [19,22], but we do not know what will be said half a century from now about Disability Studies in Education (DSE) of the early 21st century. DSE may, in retrospect, be seen as laudatory or horrific, insightful or naïve, or perhaps twisted into something grotesque. Commenting on attitudes toward the work of Nazi physician Josef Mengele, Gopnik [23] wrote:

All ideas, and ideals, are capable of being twisted into their opposites. Religious doctrines preaching nonviolence and loving thy enemy quickly turn into a search for enemies not to love. The intention and its perversion are usually transparent. We even have a good word for this bad practice: hypocrisy. But scientific theories, which get their credibility from the ability to explain the action of a limited domain of objects, can explode into false models for unrelated subjects without conscious hypocrisy. The Darwinian idea of the struggle for existence, designed to explain the chiseling of birds' beaks, becomes in a generation the idea that poor people deserve to be poor. Einstein's ideas that the measurement of time is relative can warp into the idea that morality is also relative. The missteps can be hard to track. The perversion of a scientific practice takes a second; its rectification takes a semester.

(pp. 77-78)

Guessing how various aspects of our generation's attitudes and opinions will be evaluated a century hence is therefore difficult [24]. Perhaps future generations will wonder how we could possibly make certain claims about disabilities and their meanings. They might wonder how we could confuse diversities and not see how disabilities are not like many other forms of diversity, such as color and sexual orientation, when it comes to teaching and learning. Or, perhaps, they will wonder how we could not see that all diversities are essentially the same when it comes to education. Perhaps they will wonder why we did not understand that the only limits of education were imagination and creativity. Or, perhaps, they will wonder why we did not see that education has its limits, that although it can do many things, it cannot do all things, that there are boundaries that constrain it, realities with which it must make peace or destroy itself. They may wonder why, given the necessity of identifying, labeling, and categorizing, people of our era did not see the importance of weighing disadvantages and advantages of doing so. Moreover, it is possible that special education will be destroyed or destroy itself, while inclusive general education will become the dominant approach, if not the only kind of public education left standing $[17,18]$.

The kind of education that prevails will depend in part on what "sells"; that is, what captures the public imagination and wins the public trust or popularity contest that results in public policy. Special education does not sell well unless it has at least the patina of something that has been designed for everyone- that has limitless applications to students' education and, therefore, is best for all students.

\section{On Limitlessness, Rejection of Current Wisdom, and Futures}

Something "limitless" sells much better than anything "limited." Limitlessness is associated with strength, newness, flexibility, and desirability. It suggests a limitless future, one of excitement and as-yet-unimagined progress. Limitedness is associated with the old, outdated, weak, and clumsy. It suggests a future of no excitement, merely the same old thing. Many assume that the mind-boggling limits or seeming limitlessness of the natural sciences could be found in the social sciences as well. They call, for example, for transformational changes in education in which at least some supposed limits do not apply [25]. 
Important here is recognition of the fact that although rationality has limits, irrationality does not. Nonsense has no limits. Physicists have seen the humor of this fact and mocked the idea of limitlessness with statements like "Speed Limit: 186,000 miles per second. IT'S THE LAW!" Other scientists have noted how a patina of newness and limitlessness have seduced many to embrace nonsense as if it were not [26,27]. Limitless nonsense has also found its critics in philosophy [28-30] and literary criticism [31].

Educators, too-including special educators—have joined what might be called the "limitless craze," proposing ideas that at first seem attractive and somehow achievable [32]. With more thinking and evidence, however, these ideas are exposed as fraudulent or nonsensical [33-35]. Part of the problem is merely recognizing the differences between the limitless and the limited in both the natural world and human endeavors. Postmodernism, "alternative facts," religious beliefs, and human imagination have no known limits. Science and the known world of scientific fact do have limits, as does logic.

The universe may well be limitless, but the speed of light is not, nor are many other characteristics of the physical world. In the natural world, imagination that the speed of light, gravity, or evolution are merely artificial barriers does not make them cease to exist. The human imagination may well be limitless, but the social world of human beings is not. One problem of social structures is that although they may be extremely varied —and imagination of them is limitless-the actual social world is not limitless. True, some of the realities of the social world simply can be imagined not to exist, but their reality does not therefore go away.

In the matter of the inclusion of students with disabilities in education, educators are encouraged to imagine a system of education that is limitless, in the sense that all children with disabilities will be included in general education - that is, no more special schools, classes, or places for any children with disabilities, because regular or general education will become so flexible and differentiated that there will be no limits to its accommodation of and appropriateness for students with disabilities, regardless of the nature or severity of their special needs. Special education will become a thing of the past as general education becomes inclusive of all—"all means all," no exceptions [6,22,25].

Educators today are often encouraged to reimagine what schools can do, how they operate, and what they can accomplish. The assumption apparently is that if what is imagined is different from current practices, then it can and will be realized eventually. This is especially the case if what is promised is something unlimited (e.g., "all means all," typically used to mean that all students, no exceptions, can be taught together) and runs contrary to current beliefs, particularly the belief that some children are better taught a different curriculum and/or in a different place than most.

A common theme in many proposals to reform education is opposition to mainstream thinking, rejection of current assumptions, and push-back against ideas considered old, outdated, or captives of the status quo. Proponents of alternatives may believe that attacking existing structures or current practices is both urgent and rational. So, statements like the following are thought to apply to the matter of teaching all students the same ideas in the same place and at the same time:

If we want to change the world [then] we need to be unrealistic, unreasonable, and impossible. Remember: those who called for the abolition of slavery, for suffrage for women, and for same-sex marriage were also once branded as lunatics. Until history proved them right. [36] (p. 264)

This statement may well apply to the notions mentioned-things obviously possible, though opposed by many (slavery, women's suffrage, same-sex marriage) — but the statement does not apply to the case of all students with disabilities because of the nature of the problem under consideration. The case of schooling and the objective of eliminating special education as a way of responding to educational differences reminds us of a Galileo trope [37] with quotations from Mario Livio, an astrophysicist who wrote a book about Galileo. It is almost comical irony that today's deniers try to assume the mantle of Galileo: people who disagree with the scientific consensus on things such as climate change sometimes cite Galileo as a rebel (like themselves) who is now seen as a hero. 
"It's really a logical fallacy," Livio said. "Oh, look, here was one who was going against the mainstream, and it turned out to be right: therefore, those few who speak against climate change are right. Galileo was right not because he was one against many-he was right because he was right." By this point, Livio was laughing: "It's not the case now every time that one speaks against the mainstream, he or she is right. Most of the time those people are wrong. In some rare cases, they are right. So to bring that as an argument is just ridiculous." Sadly, two arguments of very different weights can still convince a lot of people at the same rate. [37] (p. 70)

Our point here is that just because people are opposed to what they see as the evils of special education does not mean they are right. Even something like DSE and the full inclusion enthusiasm that seems to have captured attention across the world $[4,22,25,38]$ could eventually be-and we think is very likely to be-found to be a will-o'-the-wisp; that is, an enticing but impossible goal.

Another reality that cannot be imagined out of existence is the variability of students. Variability is here to stay, so our imagination can only be applied to how to deal with it. But even that imagination has some limits imposed by the realities of social and physical limits. Disability is one of those human variations related to education, but it is one that is unlike any others in its implications for instruction. It may be imagined not to exist [39], but it will not therefore cease to exist. It is in some ways like variations in parentage, cultural heritage, language, size, age, and many other diversities, but it differs from other diversities in its implications for teaching. Some disabilities have few implications for education, requiring only minor and easily made adjustments for learning (e.g., mild learning disabilities or somewhat below average quickness to learn). However, some disabilities present problems that are very difficult to accommodate and require instruction vastly different from that which is effective with most other students (e.g., severe and multiple disabilities). Moreover, all educational disabilities are directly related to teaching and learning, to effectiveness of instruction, and to the quality of life following school years.

\section{Fates of Alternative Views}

We use the term special and inclusive education because we think that the education of students with disabilities should be inclusive in ways that maintain the appropriateness of education as the priority, and do not violate the principle of individualized decisions about education. Given these requirements, special education is an indispensable component of inclusive education. For many and perhaps most students with disabilities, appropriate and special instruction in general education is possible. For others, it is not. Deciding a student's placement for education requires a judgment call. Human judgment is fallible, so errors of judgment will always be $>0$. However, elimination of judgment, too, guarantees that errors will be $>0$. Our best strategy in the case of the inclusion of students with disabilities in general education seems to be using judgment but trying to keep errors as close as possible to zero [24].

Some observers of contemporary education see other reasons for the obvious enthusiasm for total or full inclusion, and we quote the statement of a friend who will remain anonymous:

Over the years I developed a sense that there are people in the education community (in all areas, and at all levels) who are guided by nothing more than self-interest and dogma. I used to think they had an ideology, but it became clear to me that some elements within the inclusion 'movement' have neither the appetite for, interest in, nor capacity for constructive argument; they seek only to push their threadbare, evidence-lite drivel down everyone else's throats, and without a single thought for the young people's lives that are blighted by their poorly formulated ideas.

Special education is-both by American law (the Individuals with Disabilities Education Act, dating from 1975) and traditional concern for the education and well-being of students with 
disabilities-focused on the individual, not the general population of students. It is because educators must say of certain students with characteristics that are not shared by all, "This one, not that one."

Even when some plan for education that is seen as more inclusive of children with disabilities, such as the Response to Intervention (RTI), which involves judging students' responses to instruction or intervention, or the Multi-Tiered System of Supports (MTSS) or Positive Behavior Interventions and Supports (PBIS), the educator must decide what to do with or for the individual, not a group. Variance among students in what they know and need to learn will not go away, and the question educators must consider is how best to respond to such variation. Trying to obscure differences among students, including those we call disabilities, will not make them irrelevant to teaching. However, alternative views of the ways disabilities are best addressed in schooling are relevant to instruction.

The proponents of plans in which all students with disabilities are taught along with their age peers without disabilities, as well as those who propose alternatives, eventually must specify various aspects of implementation of their ideas (i.e., how what they propose will work out in practice). For example, questions like the following must be addressed:

Will students be identified as needing something other than that provided for all students, and, if so, by whom and how?

Will students, if identified as needing something different from the typical, be taught by the same teacher and study the same curriculum as their age peers who have not been identified?

Will students identified as having special educational needs ever be taught by a specially trained teacher and, if so, as determined by whom and how?

Will any students identified as having special educational needs be taught in a place other than the general education classroom and, if so, how will that be determined?

How is disability the same as and different from other forms of difference or diversity for purposes of education, and how is education different from other life activities (i.e., how is access to education different from and the same as access to all other activities in which a person might engage)?

Everyday practices (the nitty-gritty of any philosophy that guides what people do) ultimately determine the fates of alternative views of disabilities. In education, talking and writing about philosophies ultimately must face the music of action - what we actually do with students. For example, how exactly will the needs of a student with profound and multiple learning difficulties, for whom independent living skills, including toileting and feeding, is of central importance, be met in the context of the general education curriculum, particularly at secondary school level?

Perhaps the coronavirus pandemic most starkly brought to light the differences between "alternative facts" and science, the difficulties in practice based on magical thinking or social construction of realities rather than empirical evidence. The politicization in the USA of such things as wearing face masks and other responses to COVID 19 contributed to many unnecessary infections and deaths. We support the idea that the politicization of educational inclusion is most unfortunate and inconsistent with meeting the individual educational needs of students with disabilities [38].

Unfortunately, political statements may call for full inclusion without defining it, ignore special education altogether, or fail to address the issue of quality and appropriate education for students with disabilities-for example, the United Nations' Convention on the Rights of Persons with Disabilities [3,4]. Political statements may be consistent with DSE, but not with special and inclusive education. Eventually, philosophical commitments to inclusion require that educators consider their practical, reality-based implications.

\section{Practical Considerations in Special and Inclusive Education}

Some of the practical considerations in special and inclusive education are a consequence of trying to extend or apply unsuitable, inapplicable scientific principles or philosophies to educational problems. For example, some have tried to apply "the new physics," including the Heisenberg uncertainty principle and other principles or findings of the physics of subatomic particles, to social and educational problems-ideas, findings, and principles that have no implications whatsoever to 
the macro-physical and social world in which we live and function [40]. Similar problems seem to accompany attempts to apply "postmodern" and DSE philosophies to education-no application to the everyday work of teachers, no practical applications to the nitty-gritty of instruction [33-35,41]. For example, DSE notions of social justice have been used to argue that special education has become the problem and that any supposed "problem" of disability in education is with the teacher and the structure of education or failure of educators to understand disabilities from the point of view of those who have them and/or failure to recognize the strengths that pupils with disabilities bring to schools [42]. Yet, in this, no other practical suggestions were offered for reforming education or teaching, merely complaining that special education is characterized by "traditional skill-based direct instruction" [42] (p. 424).

We wish special education did reliably, predictably, and consistently provide skill-based direct instruction, for that is precisely what scientific evidence consistently has shown is most effective in teaching students with disabilities [41,43-45]. In all cases of DSE-based statements regarding instruction and inclusion, we find a lack of attention to practical application with failure to provide nitty-gritty detail of how the philosophy will be applied and how the teachers will say or not say "Yes, this one, not that one" about individuals that are to receive particular supports. The upshot is that practical matters are avoided in favor of a general, hazy philosophy that suggests individualization while side-stepping it. For example, the following conclusion is typical:

Because all students are different and all students have needs, learning supports must be embedded seamlessly into the general education classroom, not tacked on or subcontracted out. When supports are embedded and integrated into the general education classroom, they can be made available to support any or all students who need them, whenever they need them .... Of course, ideally our classroom structures and instructional practices would be universally designed to maximize the degree of fit between all students and the learning context—providing students with differentiated, meaningful, and challenging curriculum, along with high-access instruction, targeted support structures, and choice. [42] (p. 427)

In our judgment, those who propose the end of special education and the inclusion of all students in a common curriculum and site of education - that general education might be made appropriate for all learners-live in a fantasy world created by philosophical constructions and science fictions, that is inconsistent with real-world limitations. It is noted that full inclusion makes about as much sense as supposing that a single type of operator's license should allow all drivers to operate any non-airborne vehicle, that all pilots should be expected to be competent to fly all airplanes for all purposes, that all builders will be licensed to construct any building of any type, that all physicians will be able to perform all medical treatments, that all persons with a law degree should be able to handle all cases involving law, regardless of the nature of the case, and so on [46]. Specialization is understood by most people to be important in most lines of work. Of course, specialization can be taken to absurd, silly extremes, but it is recognized as important in most occupations and professions, and for good reason.

Why, we might ask, would anyone familiar with teaching and schools believe no specialization in training or practice is required to teach children with disabilities, simply because good teaching is good teaching? True, some of the same things are required in all cases; there are, indeed, core competencies required for the competent practice of teaching, regardless of the student. There are, also, core competencies required for driving, flying, building, practicing medicine, operating a hospital, serving in the armed forces, practicing law or dentistry, and many other endeavors. We realize that in each of these, the practitioner cannot be expected, should not be expected, is not by law or consensus expected to be competent in all areas of specialization. We need not belabor the points that specialization is important in every profession, that special training is critical for competent practice of that specialization, or that people get really good at doing something by applying their special training over and over as a specialist. That teaching special education is considered so nonspecialized that a single endorsement or certificate is sufficient is, in our opinion, laughably outrageous. Such a proposal 
is not only unconscionable but reveals the devaluation of what special educators do and what students with disabilities deserve. The trope "all children are special" deserves another: 'some are more special than others' [46] (pp. 258-259).

The proposal to rid schools of special education is, in our opinion, a most curious outlier, a totally nonsensical and impractical notion that has no logical justification in the real world of education that involves human beings who are teachers and students. It has the potential to prevent many children with disabilities from getting an education best suited to their needs.

\section{Concluding Comments}

We believe that inclusion in the sense of students being physically present in general education classrooms, what has been called habeas corpus inclusion, is not as important as inclusion in the sense of being engaged in a program of instruction that is meaningful and challenging for the individual, what has been called proprium instructio [47]. Appropriate instruction is by far the most important task of education for all students, including those with disabilities. Making appropriate instruction a reality for all students requires special education, including teachers with special training, rather than a generic, "one size fits all" or all-purpose preparation.

The anti-mask movement in reaction to COVID-19 restrictions comes to mind as we contemplate attitudes toward special education. Anti-mask activists abandon scientific evidence of the effectiveness of masks in preventing the spread of the virus, saying they consider being forced to wear a mask contravenes their human rights to freedom of choice, even though this puts both themselves and others at risk. They value their personal freedom more than rational consideration of scientific evidence and being considerate to the safety and human rights of others. They therefore begin any logical discussion holding false premises about human rights. We see the same problems of muddled thinking and science denial in the DSE, special-education-as-disservice movement, and in the related assumption that special education is second-rate and demeaning.

One irony of the constructivist DSE version of education is that it spurns the very direct instruction methodology that is the most promising for all students, one that would make meaningful inclusion of more students with disabilities more successful. Unfortunately, many individuals' comments about their educational experiences are misleading when taken as indications of what is desirable or undesirable or for their benefit, particularly their long-term benefit. Certainly, individuals' preferences and comments about their personal experiences are important and should be considered. However, children and adolescents often express hostility toward necessary and beneficial discipline, control, direction, work, and education and choose patterns of behavior that are unacceptable and self-injurious in their ultimate consequences. Such consequences include eventualities that are not socially constructed but constraints of the natural world.

Perhaps the coronavirus has provided an apropos example of why scientific data and their logical interpretation are important and apply to special and inclusive education as well as to virology and human health. Most people can see the logical fallacy in the suggestion that cases of COVID-19 exist only because we test for it and that if we simply did not test so many people we would have a lower rate of infection. To us, that is no more laughable than the idea that if we did not test and then label so many students as having disabilities or special educational needs we would have fewer of them.

The Black Lives Matter (BLM) movement of 2020 provides a cautionary example of what is at stake in labeling and categorizing. Of course, it is true at one level that all lives matter, but that truism is used by some as a distraction from BLM, a way of diminishing the necessary focus on Black lives. Naming the category or the individual does not guarantee that a particular issue will be addressed [48]. That is, it is not a sufficient condition for change, but it is a necessary condition-the change will not occur without it. We might note that the plight or needs of minorities, including those with disabilities as well as those of color, will be ignored if their category is not labelled-named. And names-labels-apply to individuals, not only to categories in their abstraction. 
The truly horrifying thing to us is the lack of understanding of people who consider themselves advocates for students with disabilities regarding the fact that if people are not identified and given labels, they are likely to be ignored. In the real world, students judged to have no disabilities or deficits, will have no special programs, but will only have access to programs developed for all students. Remember, all lives matter, though true, removes the focus on Black lives. Likewise, the argument that all students are special, though true in some sense, removes the focus on students with disabilities. Only in a fantasy world is difference in ability so unimportant that no individual is considered typical, gifted, or to have a disability in any area of functioning, including school or education. Some imaginary worlds are dystopian, and one in which disability is thought to be universal, inconsequential, or even desirable when all social barriers are removed is, in our opinion, not only unrealistic but dystopian.

Our hope is to make the real world a better, more habilitative place for students with disabilities. In contrast to a focus on full inclusion that denies many children with disabilities an appropriate education, the application of evidence-based special education strategies will help to ensure that all young people with special educational needs and disabilities get an education that optimizes their educational outcomes and provides them with the greatest chance of being fully included in their communities after leaving school. A recent review of the literature on the effectiveness of educating children with disabilities has suggested that, in order to provide them with an equitable and excellent education, implementation of a synthesis of key components of special education and inclusive education is needed [49]. This review proposes that key special education strategies and approaches must co-exist with those from inclusive education in order to provide effective education for all young people with special educational needs and disabilities. One way to do this is within a model of inclusive special education which combines key elements of special education with those from inclusive education [44].

Therefore, it is considered that, rather than becoming extinct, special education needs to continue to be developed through ongoing development and evaluation of interventions, to be disseminated as widely as possible through the education and training of teachers and other professionals who work with young people with special educational needs and disabilities, and to be rigorously implemented and evaluated in schools at all levels of education systems.

Author Contributions: Conceptualization, G.H.; Writing—original draft, J.M.K. and G.H.; Writing一review \& editing, J.M.K. All authors have read and agreed to the published version of the manuscript.

Funding: This research received no external funding.

Conflicts of Interest: The authors declare no conflict of interest.

\section{References}

1. UNCRPD (United Nations Convention on the Rights of Persons with Disabilities). 2016. Available online: https:// www.un.org/development/desa/disabilities/convention-on-the-rights-of-persons-with-disabilities.html (accessed on 12 August 2020).

2. Cook, B.G.; Cook, L. An examination of highly cited research on inclusion. In On Educational Inclusion: Meanings, History, Issues and International Perspectives; Kauffman, J.M., Ed.; Routledge: New York, NY, USA, 2020; pp. 130-159.

3. Anastasiou, D.; Gregory, M.; Kauffman, J.M. Commentary on Article 24 of the CRPD: The right to education. In Commentary on the UN Convention on the Rights of Persons with Disabilities; Bantekas, I., Stein, M., Anastasiou, D., Eds.; Oxford University Press: New York, NY, USA, 2018; pp. 656-704.

4. Anastasiou, D.; Felder, M.; Correia, L.; Shemanov, A.; Zweers, I.; Ahrbeck, B. The impact of Article 24 of the CRPD on special and inclusive education in Germany, Portugal, the Russian Federation, and Netherlands. In On Educational Inclusion: Meanings, History, Issues and International Perspectives; Kauffman, J.M., Ed.; Routledge: New York, NY, USA, 2020; pp. 236-245.

5. Hyatt, C.; Hornby, G. Will UN Article 24 lead to the demise of special education or to its re-affirmation? Support Learn. 2017, 32, 288-304. [CrossRef] 
6. UNESCO (United Nations Educational, Scientific and Cultural Organization). Inclusion and Education: All Means All. Global Education Monitoring Report. 2020. Available online: https://unesdoc.unesco.org/ark: /48223/pf0000373718 (accessed on 12 August 2020).

7. Kauffman, J.M. The special education story: Obituary, accident report, conversion experience, reincarnation, or none of the above? Exceptionality 2000, 8, 61-71. [CrossRef]

8. Zigmond, N.P.; Kloo, A. General and special education are (and should be) different. In Handbook of Special Education, 2nd ed.; Kauffman, J.M., Hallahan, D.P., Pullen, P.C., Eds.; Routledge: New York, NY, USA, 2017; pp. 249-262.

9. Hornby, G. Inclusive special education: Development of a new theory for the education of children with special educational needs and disabilities. Br. J. Spéc. Educ. 2015, 42, 234-256. [CrossRef]

10. Hornby, G. Inclusion or Delusion: Can one size fit all? Support Learn. 1999, 14, 152-157. [CrossRef]

11. Kauffman, J.M. Appearances, Stigma, and Prevention. Remedial Spéc. Educ. 2003, 24, 195-198. [CrossRef]

12. Kauffman, J.M. Truths and their implications for special education policy and practice. J. Disabil. Policy Stud. 2020. Manuscript submitted for publication.

13. Kauffman, J.M.; Hallahan, D.P.; Pullen, P.C. Creeping normality: Special education's problem of a new normal. J. Disabil. Policy Stud. 2020, in press.

14. Kidd, R.; Hornby, G. Transfer from special to mainstream. Br. J. Spec. Educ. 1993, 20, 17-19. [CrossRef]

15. Hornby, G.; Kidd, R. Transfer from special to mainstream-Ten years later. Br. J. Spec. Educ. 2001, $28,10-17$. [CrossRef]

16. Kauffman, J.M. Has Inclusion Gone Too Far? Reflections on change and progress. Rethink. Behav. 2019, 2, $11-16$.

17. Kauffman, J.M.; Anastasiou, D.; Badar, J.; Hallenbeck, B.A. Becoming your own worst enemy: Converging paths. In Inclusive Education: Global Issues \& Controversie; Boyle, C., Mavropoulou, S., Anderson, J., Page, A., Eds.; Brill Sense: Boston, MA, USA, 2020; pp. 73-88.

18. Kauffman, J.M.; Ahrbeck, B.; Anastasiou, D.; Badar, J.; Felder, M.; Hallenbeck, B.A. Special Education Policy Prospects: Lessons from Social Policies Past. Exceptionality 2020. [CrossRef]

19. Lipsky, D.K.; Gartner, A. Inclusion, school restructuring, and the remaking of American society. Harv. Educ. Rev. 1996, 66, 762-796. [CrossRef]

20. Gerber, M.M. A history of special education. In Handbook of Special Education, 2nd ed.; Kauffman, J.M., Hallahan, D.P., Pullen, P.C., Eds.; Routledge: New York, NY, USA, 2017; pp. 3-15.

21. Kauffman, J.M. Attributions of malice to special education policy and practice. In Advances in Learning and Behavioral Disabilities Policy and Practice; Scruggs, T.E., Mastropieri, M.A., Eds.; Emerald: Bingley, UK, 2009; Volume 22, pp. 33-66.

22. Slee, R. Defining the Scope of Inclusive Education. Technical Report. Available online: https://www. researchgate.net/publication/330741940 (accessed on 18 May 2020).

23. Gopnik, A. Measuring Man: Josef Mengele's malignant "science". The New Yorker, 22 June 2020; 77-81.

24. Kristof, N. The mistakes that will haunt our legacy. The New York Times. Available online: https://www.nytimes.com/2020/07/11/opinion/sunday/animal-rights-cruelty.html?action=click\&module= Opinion\&pgtype=Homepage (accessed on 11 July 2020).

25. SWIFT Schools. Available online: https://swiftschools.org (accessed on 10 June 2020).

26. Gross, P.R.; Levitt, N.; Lewis, M.W. The Flight from Science and Reason; Johns Hopkins University Press: Baltimore, MD, USA, 1996.

27. Sokal, A.; Bricmont, J. Fashionable Nonsense: Postmodern Intellectuals' Abuse of Science; Picador: New York, NY, USA, 1998.

28. Blackburn, S. Truth: A Guide; Oxford University Press: New York, NY, USA, 2005.

29. Koertge, N. A House Built on Sand: Exposing Postmodernist Myths about Science; Oxford University Press: New York, NY, USA, 1998.

30. Neiman, S. Moral Clarity: A Guide for Grown-Up Idealists; Harcourt: New York, NY, USA, 2008.

31. Crews, F. Postmodern Pooh; North Point Press: New York, NY, USA, 2001.

32. Gallagher, D.J. Challenging Orthodoxy in Special Education: Dissenting Voices; Love: Denver, CO, USA, 2004.

33. Mostert, M.P.; Kavale, K.A.; Kauffman, J.M. Challenging the Refusal of Reasoning in Special Education; Love: Denver, CO, USA, 2008. 
34. Sasso, G.M. The retreat from inquiry and knowledge in special education. J. Spec. Educ. 2001, 34, $178-193$. [CrossRef]

35. Sasso, G.M. Science and reason in special education: The legacy of Derrida and Foucault. In Achieving the Radical Reform of Special Education: Essays in Honor of James M. Kauffman; Crockett, J.B., Gerber, M.M., Landrum, T.J., Eds.; Erlbaum: Mahwah, NJ, USA, 2007; pp. 143-167.

36. Bregman, R. Utopia for Realists and How We Get There; Bloomsbury: London, UK, 2017.

37. Mirsky, S. Denial du jour: Galileo's fights against science deniers have modern-day analogues. Sci. Am. 2020, 323, 70 .

38. Ahrbeck, B.; Felder, M. The Politicization of Education: A Perspective from Germany. CIEO. Available online: https://www.cieo.org.uk/research/politicisation-of-education/ (accessed on 24 July 2020).

39. Baglieri, S.; Bejoian, L.M.; Broderick, A.A.; Connor, D.J.; Valle, J. [Re]claiming "inclusive education" toward cohesion in educational reform: Disability studies unravels the myth of the normal child. Teach. Coll. Rec. 2011, 113, 2122-2154.

40. Kauffman, J.M. Education Deform: Bright People Sometimes Say Stupid Things about Education; Rowman \& Littlefield Education: New York, NY, USA, 2002.

41. Kauffman, J.M. Toward a Science of Education: The Battle between Rogue and Real Science; Attainment: Verona, WS, USA, 2011.

42. Ferri, B. Doing a (dis)service: Reimagining special education from a disability studies perspective. In Handbook of Social Justice in Education; Ayers, W., Quinn, T.M., Stovall, D., Eds.; Taylor \& Francis: New York, NY, USA, 2008; pp. 417-430.

43. Bateman, B.D.; Lloyd, J.W.; Tankersley, M. Enduring Issues in Special Education: Personal Perspectives; Routledge: New York, NY, USA, 2013.

44. Hornby, G. Inclusive Special Education: Evidence-Based Practices for Children with Special Needs and Disabilities; Springer: New York, NY, USA, 2014.

45. Walker, H.M.; Gresham, F.M. Handbook of Evidence-Based Practices for Emotional and Behavioral Disorders: Applications in Schools; Guilford: New York, NY, USA, 2014.

46. Kauffman, J.M.; Hallahan, D.P.; Landrum, T.J.; Smith, C.R. Likely legacies of inclusion. In On Educational Inclusion: Meanings, History, Issues and International Perspectives; Kauffman, J.M., Ed.; Routledge: New York, NY, USA, 2020; pp. 249-265.

47. Kauffman, J.M.; Badar, J. Definitions and other issues. In On Educational Inclusion: Meanings, History, Issues and International Perspectives; Kauffman, J.M., Ed.; Routledge: New York, NY, USA, 2020; pp. 1-24.

48. Attiah, K. Black Lives Matter isn't complete without \#SayHerName. The Washington Post, 21 July 2020, p. A25.

49. Hornby, G. The necessity for coexistence of equity and excellence in inclusive and special education. In Encyclopedia of Inclusive and Special Education; Oxford University Press: New York, NY, USA, 2020; in press. 